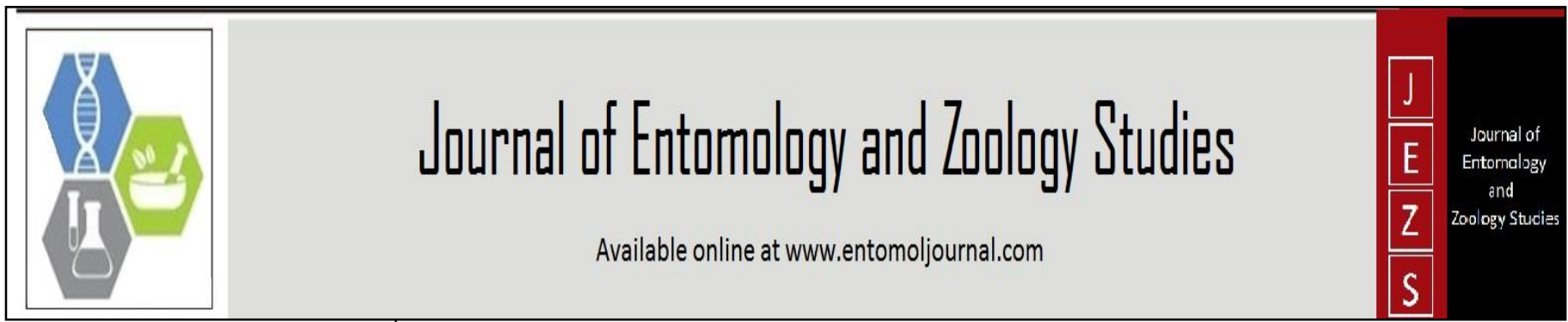

E-ISSN: 2320-7078

P-ISSN: 2349-6800

JEZS 2018; 6(3): 1232-1234

(C) $2018 \mathrm{JEZS}$

Received: 19-03-2018

Accepted: 20-04-2018

Mark Ian Cooper

School of AP\&ES,

University of the Witwatersrand,

Braamfontein 2017,

Johannesburg, RSA

South Africa
Correspondence

Mark Ian Cooper

School of AP\&ES,

University of the Witwatersrand,

Braamfontein 2017,

Johannesburg, RSA,

South Africa

\section{Trigoniulid size dimorphism breaks Rensch}

\section{Mark Ian Cooper}

\section{Abstract}

This present research aims to clarify the relative sexual size dimorphism of Centrobolus (Cook) in 18 congenerics. Millipedes illustrated reversed sexual size dimorphism (SSD) where females were larger than males; and break Rensch's rule as this dimorphism increased with body size. SSD was calculated in 18 species of the genus Centrobolus and illustrated was illustrated in 2 regressions: (1) male versus female SSD and (2) SSD and body size. The allometric equation for Centrobolus was (1) $\hat{\mathrm{y}}=0.00051 \mathrm{X} 0.01071$. SSD ranged from $0.63-2.89(1.55 \pm 0.63 ; \mathrm{n} \geq 18)$ and was not negatively correlated $\left(\mathrm{R}=0.70485 ; \mathrm{P}=0.00109 ; \mathrm{n}=18 \mathrm{spp}\right.$.) with a volumetric index of body size ranging from $284-2683 \mathrm{~mm}^{3}$ $(1097.89 \pm 638.06 ; 18)$. The rejection of the rule appears consistent in some animals.

Keywords: Dimorphism, millipede, SSD, size

\section{Introduction}

Sexual size dimorphism (SSD) is prevalent in arthropods and females are usually larger than males e. g. Ammothea hilgendorfi ${ }^{[1]}$; Limnebius ${ }^{[2]}$. Behavioural patterns such as provisioning versus non-provisioning relate to SSD ${ }^{[3]}$. Millipedes illustrate reversed SSD and females are larger than males ${ }^{[4-9]}$. SSD in forest millipedes has successfully been understood as volumetric measurements using Centrobolus to reject Rensch's rule ${ }^{[4-7]}$. This rule maintains there should be a negative relationship between body size and SSD when females are larger, which is often not the case in Invertebrates ${ }^{[14]}$. Based on equal developmental rates in males and females, the proximate cause for Rensch's rule is sexual bimaturism ${ }^{[10-11,14]}$. The general trend of SSD has been calculated for Centrobolus and bimaturism shown ${ }^{[7,11]}$. The present study was aimed to illustrate the trend of SSD for the genus Centrobolus in 18 congenerics in order to highlight how males and females disobey the trend of Rensch's rule.

The trends for this allometric rule when females are larger than males as is the case in almost all orders of Diplopoda is a negative one. Thus it can be expected there will be a negative relationship between SSD and body size. However, this is most often not the case in animals like invertebrates and revision of higher taxa above species relationships is now being clarified. The combined results from two previously published papers are illustrated here together in order to clarify the result of a test of Rensch's rule in the fire millipede genus Centrobolus.

\section{Materials and Methods}

Two factors were measured from Centrobolus species (1) body length (mm) by placing individuals collected in South Africa (1998-2018) alongside a plastic rule (calibrated in mm); and (2) width (mm) with Vernier calipers was measured in South Africa (1998-2018). Millipede SSD was calculated in the genus Centrobolus ${ }^{[4,7]}$. A regression of male volume on female volume was used to show the position of 18 species and the volumetric measurements inserted into a Microsoft (MS) Excel spreadsheet and converted using the logarithmic (mathematical) equation. The chart for SSD in 18 species was captured, copied and exported using the snapshot function in the programme Soda Portable Document File (PDF) Desktop on a Proline computer (Model No IP-S600AQ3-0). It was pasted into the Microsoft file.

\subsection{Statistical Analysis}

The basic descriptive figures were statistically compared using Statistica. Body length: width ratios were compared on arcsine transformed data. The mean values of length and width was extracted from published data for 18 species intersexual comparisons performed using Wilcoxon matched pairs tests. Size was perceived as body volume and calculated based on the 
formula for a cylinder $\left(l \cdot \pi \cdot r^{2}\right)$ where $l$ is body length and $r$ half of the width. SSD was estimated as the mean female volume divided by mean male volume and converted into a SSD index by subtracting 1 . Allometry for SSD was based on a general allometric model where male size $=\alpha(\text { female })^{\beta}$.

\section{Results}

The quantitative resolution of Rensch's rule for 18 species of Centrobolus is shown in Fig. 1. The positive relationship between SSD and body size is shown in Fig. 2. The allometric equation for Centrobolus was (1) $\hat{y}=0.00051 X 0.01071$. SSD ranged from $0.63-2.89(1.55 \pm 0.63 ; \mathrm{n} \geq 18)$ and was not negatively correlated ( $\mathrm{R}=0.70485 ; \mathrm{P}=0.00109 ; \mathrm{n}=18$ spp.) with volume ranging from $284-2683 \mathrm{~mm}^{3}$ (1097.89 \pm 638.06 ; 18).

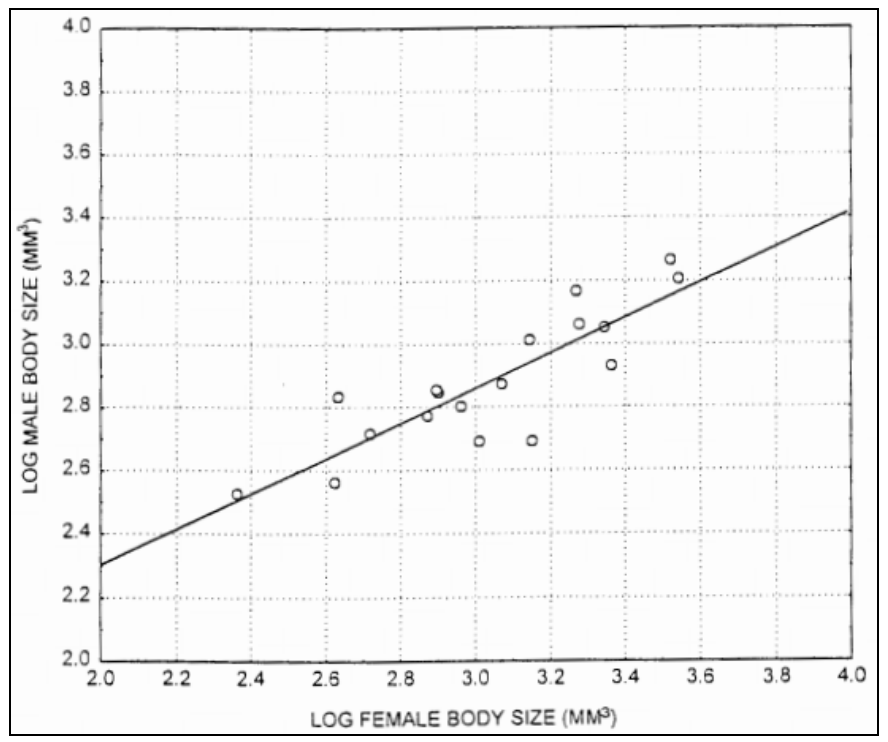

Fig 1: Quantitative resolution of Rensch's rule for 18 species of millipedes of the genus Centrobolus. Allometry for sexual size dimorphism (SSD) is based on the general model ${ }^{[12-13]}$, male size $=$ $\alpha$ (female size $)^{\beta}$; correlation coefficient, $r=0.85$. The regression of $\log$ (female size) on log (male size) would generate an identical relationship with $\beta<1$.

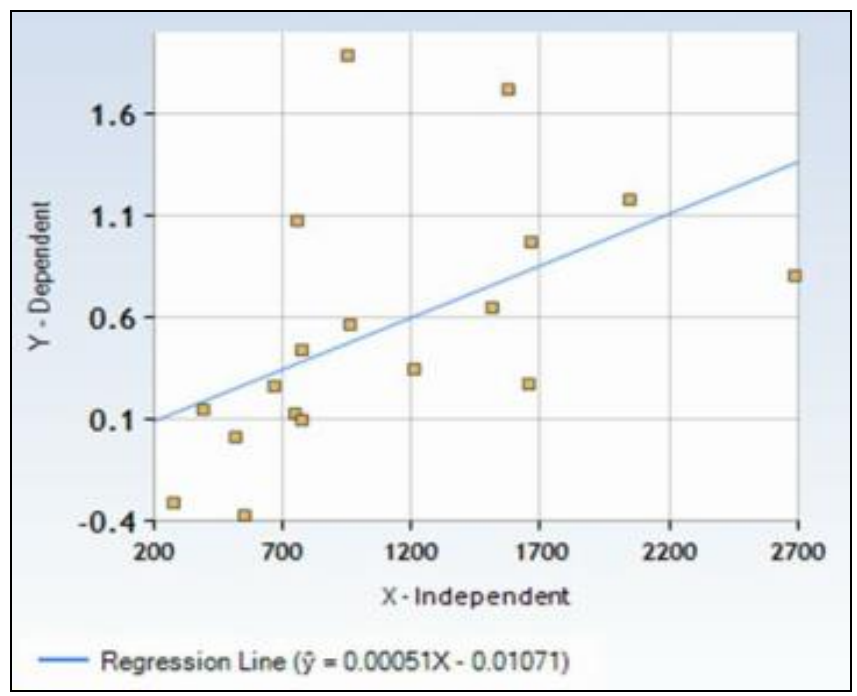

Fig 2: Regression showing the relationship between sexual size dimorphism and body size (volume) in Centrobolus ${ }^{15}$.

\section{Discussion}

The results consistently reject Rensch's rule. Figure 1 shows the finding for Centrobolus where mean volume ratios ranged from 0.63-2.72 with the regression of log male volume on log female volume was highly significant with a positive slope less than 1; showing females get larger than males with an increase in body size ${ }^{[4,7,9]}$. The mean volume ratio of above 1.0 was a trend for the genus. This study is similar to numerous studies which have found animal families having female biased SSD mostly disobey Rensch's rule including acciptridae, anatids, anguids, apodids, ardeids, bufonids, caprimulgids, chameleonids, charadriids, columbids, corvids, cracids, cuculids, fringillids, falconidae, funariidae, gasterosteids, glareolids, gripopterygids, gruids, hydropsychids, larids, muscicapids, odontophorids, passerids, phasianids, picids, pinnipeds, psittacids, rallids, salamandrids, scolopacids, strigidae, sylviids, tenebrionids, thamnophilids, tinamids, trochilids, tyrannids, and viviparids ${ }^{[16-39]}$.

\section{Conclusion}

Centrobolus males and females break Rensch's rule as was the case in some animals.

\section{References}

1. Barreto FS, Avise JC. Polygynandry and sexual size dimorphism in the sea spider Ammothea hilgendorfi (Pycnogonida: Ammotheidae), a marine arthropod with brood-carrying males. Molecular Ecology. 2008; 17(18):4164-4175.

2. Rudoy A, Ribera I. Evolution of sexual dimorphism and Rensch's rule in the beetle genus Limnebius (Hydraenidae): is sexual selection opportunistic? Peer J. 2017; 5:e3060. DOI 10.7717/peerj.3060.

3. Shreeves G, Field J. Parental care and sexual size dimorphism in wasps and bees. Behavioural Ecology and Sociobiology. 62:843-852.

4. Cooper MI. Sexual size dimorphism and corroboration of Rensch's rule in Chersastus millipedes (Diplopoda: Trigoniulidae). Journal of Entomology and Zoology Studies. 2014; 2(6):264-266.

5. Cooper MI. Heavier-shorter-wider females in the millipede Centrobolus inscriptus (Spirobolida: Trigoniulidae). Journal of Entomology and Zoology Studies. 2016; 4(2):509-510.

6. Ilić BS, Mitić BM, Makarov SE. Sexual dimorphism in Apfelbeckia insculpta (L. Koch, 1867) (Myriapoda: Diplopoda: Callipodida). Archives of Biological Sciences. 2016; 68:1-20.

7. Cooper MI. The relative sexual size dimorphism of Centrobolus inscriptus compared to 18 congenerics. Journal of Entomology and Zoology Studies. 2016; 4(6):504-505.

8. Schubart O. Diplopoda III. In South African Animal Life. 1966; 12:1-227.

9. Lawrence RF. The Spiroboloidea (Diplopoda) of the eastern half of southern Africa. Annals of the Natal Museum. 1967; 18:607-646.

10. Blanckenhorn WU, Dixon AFG, Fairbairn DJ, Foellmer MW, Gilbert P, Van der Linde K et al. Proximate Causes of Rensch's Rule: Does Sexual Size Dimorphism in Arthropods Result from Sex Differences in Development Time? The American Naturalist. 2007; 169(2):245-257.

11. Cooper MI. Sexual bimaturism in the millipede Centrobolus inscriptus (Attems). Journal of Entomology and Zoology Studies. 4(3):86-87.

12. Leutenegger W. Scaling of sexual dimorphism in body size and breeding system in primates. Nature. 1978; 272:610-611.

13. LaBarbera M. Analyzing Body Size as a Factor in 
Ecology and Evolution. Annual Review of Ecology and Systematics. 1989; 20:97-117.

14. Webb TJ, Freckleton RP. Only Half Right: Species with Female-Biased Sexual Size Dimorphism Consistently Break Rensch's Rule. PLoS ONE. 2007; 2(9):e897.

15. Cooper MI. Re-assessment of rensch's rule in Centrobolus. Journal of Entomology and Zoology Studies. 2017; 5(6):2408-2410.

16. Lindenfors P, Tullberg BS, Biuw M. Phylogenetic analyses of sexual selection and sexual size dimorphism in pinnipeds. Behavioural Ecology and Sociobiology. 2002; 52:188-193.

17. Monnet JM, Cherry MI. Sexual size dimorphism in anurans. Proceedings of the Royal Society of London B Biological Sciences. 2002; 269(1507):2301-2307.

18. Jannot JE, Kerans BL. Body size, sexual size dimorphism, and Rensch's rule in adult hydropsychid caddisflies (Trichoptera: Hydropsychidae). Canadian Journal of Zoology. 2003; 81:1956-1964.

19. Tubaro PL, Bertelli S. Female-biased size dimorphism in tinamous: A comparative test fails to support Rensch's rule. Biological Journal of the Linnean Society. 2003; 80:519-527.

20. Rutherford PL. Proximate mechanisms that contribute to female-biased sexual size dimorphism in an anguid lizard. Canadian Journal of Zoology. 2004; 82(5):817822.

21. Teder T, Tammaru T. Sexual size dimorphism within species increases with body size in insects. Oikos. 2005; 108:321-334.

22. Webb TJ, Freckleton RP. Only Half Right: Species with Female-Biased Sexual Size Dimorphism Consistently Break Rensch's Rule. PLoS ONE. 2007; 2(9):e89715.

23. Sutter NB, Mosher DS, Ostrander EA. Morphometrics within dog breeds are highly reproducible and dispute Rensch's rule. Mammalian Genomics. 2008; 19:713-723.

24. Stuart-fox D. A test of Rensch's rule in dwarf chameleons (Bradypodion spp.), a group with femalebiased sexual size dimorphism. Evolutionary Ecology. 2009; 23:425-433.

25. Herczeg G, Gonda A, Merilä J. Rensch's rule inverted female-driven gigantism in nine-spined stickleback Pungitius pungitius. Journal of Animal Ecology. 2010; 79:581-588.

26. Remeš V, Székely T. Domestic chickens defy Rensch's rule: sexual size dimorphism in chicken breeds. Journal of Evolutionary Biology. 2010; 23:2754-2759.

27. Minton RL, Wang in LL. Evidence of sexual shape dimorphism in Viviparus (Gastropoda: Viviparidae). Journal of Molluscan Studies. 2011; 77(3):315-317.

28. Liao WB, Chen W. Inverse Rensch-rule in a frog with female-baised sexual size dimorphism. Naturwissenschaften. 2012; 99:427-431.

29. Bidau CJ, Martí DA, Castillo ER. Rensch's rule is not verified in melanopline grasshoppers (Acrididae). Journal of Insect Biodiversity. 2013; 1(12):1-14.

30. De Lisle SP, Rowe L. Correlated Evolution of Allometry and Sexual Dimorphism across Higher Taxa. The American Naturalist. 2013; 182(5):630-639.

31. Liao WB, Zeng Y, Zhou CQ, Jehle R. Sexual size dimorphism in anurans fails to obey Rensch's rule. Frontiers in Zoology. 2013; 10(10):1-7.

32. Liao WB. Evolution of sexual size dimorphism in a frog obeys the inverse of Rensch's rule. Evolutionary Biology. 2013; 40:493-499.
33. Colleoni E, Denoël M, Padoa-Schioppa E, Scali S, Ficetola GF. Rensch's rule and sexual dimorphism in salamanders: patterns and potential processes. Journal of Zoology. 2014; 293:143-151.

34. Guillermo-Ferreira R, Novaes MC, Lecci LS, Bispo PC. Allometry for Sexual Size Dimorphism in Stoneflies Defies the Rensch's Rule. Neotropical Entomology. 2014; 43:172.

35. Husak JF, McGuire JA. Does 'gliding while gravid' explain Rensch's in rule flying lizards? Biological Journal of the Linnean Society. 2014; 113:270-282.

36. Lu D, Zhou CQ, Liao WB. Pattern of sexual size dimorphism supports the inverse Rensch's rule in two frog species. Animal Biology. 2014; 64:87-95.

37. Liao, WB, Liu WC, Merilä J. Andrew meets Rensch: sexual size dimorphism and the inverse of Rensch's rule in Andrew's toad (Bufo andrewsi). Oecologia. 2015; 177:389-399.

38. Cooper MI. The relative sexual size dimorphism of Centrobolus inscriptus (Attems) compared to 18 congenerics. Journal of Entomology and Zoology Studies. 2016; 4(6):504-505.

39. Martin OY, Michalczyk L, Millard AL, Emerson BC, Gage MJG. Lack of support for Rensch's rule in an intraspecific test using red flour beetle (Tribolium castaneum) populations. Insect Science. 2017; 24(1):133140. 